\title{
RESENHA
}

\section{O tempo constitucional em ciclos ${ }^{1}$}

\section{BALKIN, Jack. The cycles of constitutional time. New York: Oxford University Press, 2020.}

\author{
Daniel Bogéa ${ }^{2}$ \\ Universidade de São Paulo (São Paulo, São Paulo, Brasil) \\ ORCID: https://orcid.org/0000-0003-0486-9427 \\ E-mail: daniel.bogea@usp.br
}

\section{Introdução}

O professor Jack Balkin, da Escola de Direito da Universidade de Yale, é um dos mais influentes teóricos constitucionais da contemporaneidade. Sua obra mais recente, The Cycles of Constitutional Time (Oxford University Press, 2020), conforma um projeto intelectual, a um só passo, ambicioso e singelo. $\mathrm{O}$ livro maneja reflexão teórica na fronteira entre a teoria constitucional e a ciência política para lidar com a conjuntura estadunidense. Podemos posicioná-lo na prateleira dos recentes e numerosos lançamentos editoriais sobre a "crise da democracia” (e.g. GINSBURG, HUQ, 2018; LEVITSKY, ZIBLATT, 2018; PRZEWORSKI, 2019; SUNSTEIN, 2018), mas em uma reflexão com tons mais otimistas que seus pares.

Se o título sugere arco teórico passível de aplicação mais geral, o autor direciona seu enfoque ao contexto norte-americano. Não se cuida, no entanto, de contribuição válida apenas para compreender o conturbado ambiente institucional dos EUA. Em que pese o caráter aparentemente idiossincrático do empreendimento, Balkin desenvolve framework que pode ser transplantado a outros contextos, sendo útil para estruturar o debate sobre o funcionamento das instituições democráticas em diferentes realidades.

\footnotetext{
${ }^{1}$ BOGÉA, Daniel. O tempo constitucional em ciclos. Suprema: revista de estudos constitucionais, Brasília, v. 1, n. 2, p. 461-476, jul./dez. 2021.

2 Doutorando em Ciência Política na Faculdade de Filosofia, Letras e Ciências Humanas da Universidade de São Paulo. Mestre em Ciência Política pela Universidade de Brasília. Mestre em Direito Constitucional pela Universidade de São Paulo. Currículo Lattes: https://lattes.cnpq.br/5717111657536335.
} 
O livro é dividido em duas grandes partes. Na primeira seção, subdividida em cinco capítulos, o autor conecta sua teoria do tempo constitucional com o atual contexto da democracia nos EUA - caracterizado eufemisticamente como "desagrado recente" - a partir do diagnóstico de convergência de três grandes ciclos (ciclo dos regimes políticos, ciclo da polarização e ciclo da podridão constitucional). Na segunda seção, seis outros capítulos endereçam de forma mais específica o papel da Suprema Corte e do controle de constitucionalidade, conectando os três ciclos com a dinâmica do tempo judicial para refletir sobre a função de tribunais, contrapondo-se a uma visão salvacionista que atribui a juízes tarefas que escapam de suas capacidades institucionais.

\section{Os três ciclos do tempo constitucional}

Como ponto de partida, Balkin rejeita uma visão linear do tempo, que entende subjazer às mais influentes teorias sobre interpretação constitucional (particularmente, o debate estadunidense entre originalismo e constitutionalismo vivo). $\mathrm{O}$ autor lança um olhar diferente sobre a história, percebendo o andar dos fenômenos políticos e constitucionais em ciclos. Mais especificamente, cuida do tempo constitucional a partir da interação entre dois fatores: a vontade política e as estruturas institucionais. Esse processo operaria, de forma paralela, as engrenagens de três ciclos diferentes. A peculiaridade do momento atual residiria justamente na confluência de transições concomitantes em cada um desses três ciclos, em uma espécie de eclipse que caracterizaria os atuais "tempos sombrios".

O primeiro ciclo diz respeito à ascensão e queda dos regimes políticos. Aqui, Balkin toma inspiração do cientista político Stephen Skowonek. O que determina o tempo do ciclo de um regime político seria a existência de um partido dominante que consegue construir coalizão governante capaz de mantê-lo no poder por amplos períodos, construindo o espaço do possível na política e as bases da agenda pública. No caso dos EUA, Balkin divide a história constitucional em seis grandes ciclos, sugerindo que a atual conjuntura corresponde ao esgotamento do regime político iniciado com a presidência de Ronald Reagan, em uma era marcada pelas agendas de desregulação, privatização, cortes de impostos, fraqueza de sindicatos de trabalhadores, elevação de desigualdade econômica e contenção racial (BALKIN, 2020, p. 13). 
Apesar da ênfase conferida aos ocupantes da chefia do Poder Executivo, o autor também tenta atribuir força explicativa a outras variáveis. Com o passar do tempo, aberturas confeririam oportunidades para a transição rumo a um novo ciclo. Isso poderia ocorrer por conta de transformações sociais e demográficas mais amplas, ou mesmo pela ação política de lideranças. Para Balkin, o próprio ciclo temporal age lentamente para a fragilização de um regime político, com a geração de novos pontos de veto, obstáculos e conflitos de interesse. São cinco os fatores centrais para determinarmos se o ciclo de um regime político estaria chegando a seu fim: (i) partido dominante; (ii) mudanças demográficas; (iii) reorganização do sistema partidário; (iv) reorientação de objetivos e agendas de governança; e (v) mudanças de composição do Judiciário e de doutrinas impostas por tribunais (BALKIN, 2020, p. 24).

Deve-se observar que a complexidade e a multiplicidade de variáveis tornam desafiadora a tarefa empírica de investigar os mecanismos causais da ascensão e queda de regimes políticos, tanto para diagnósticos retrospectivos como para juízos preditivos mais fortes que permitam a antecipação do timing de transições em casos específicos. A própria análise do autor sobre o caso estadunidense é controversa e não é capaz de oferecer evidências incontestáveis. A caracterização das presidências democratas de Bill Clinton e Barack Obama como lideranças que não aproveitaram janelas de oportunidade para transições mais profundas, bem como a visão do mandato do republicano Donald Trump como uma tentativa de renascimento do regime inaugurado com Reagan, são teses em disputa no "mercado" de análises de conjuntura.

O segundo ciclo, por sua vez, é aquele que transita entre polarização e despolarização. $\mathrm{O}$ fato de que vivemos uma era polarizada é incontestável. Mais contestável, no entanto, é a visão encampada pelo autor, ao tratar da polarização partidária estadunidense, de que estaríamos no ápice de polarização e que haveria sinais de que um ciclo de despolarização estaria por vir nas próximas décadas. Apesar de conceder a existência de "múltiplas causas" para o fenômeno da polarização política, Balkin atribui força explicativa central para a desigualdade de renda. Ficam de lado outros aspectos da contemporaneidade que tornam o ambiente político claramente mais polarizado, como as novas tecnologias de interação social em redes. Uma avaliação comparativa poderia jogar luz sobre questões diferentes; há de se questionar se a trajetória da desigualdade no Brasil, por exemplo, coincide com a polarização do ambiente político. 
O terceiro ciclo envolve movimentos de podridão e renovação constitucional. Para dar conta desse fenômeno temporal, Balkin introduz seu conceito de crise constitucional. A possibilidade de crise está umbilicalmente ligada ao que concebe como o papel central de uma Constituição, que diz respeito à canalização de desacordos e disputas de poder para prevenir violência, guerra civil ou insurreição (BALKIN, 2020, p. 38). Para que se concretize uma crise, portanto, deveria estar configurada uma das seguintes hipóteses de colapso constitucional: (i) a não aderência explícita de agentes públicos às regras constitucionais; (ii) a aderência a uma Constituição cujos resultados são catastróficos do ponto de vista da sociedade como um todo; ou (iii) quando o desacordo sobre o significado constitucional atinge um ponto extremo de violência civil. Ou seja, a crise constitucional ocorre quando a Constituição não funciona mais como instrumento capaz de viabilizar a política. Nessa perspectiva, conflitos severos no campo político (incluindo-se a hipótese de impeachment presidencial) são parte do jogo, desde que se operem a partir de mecanismos institucionalizados pelo direito e pela política.

Se a crise é de difícil configuração, mais ordinário é o processo cíclico de degradação constitucional. Haveria uma progressiva decadência de características do sistema constitucional que sustentam seus valores democráticos (como soberania popular) e republicanos (como prevalência do bem público). Esse processo rumo à podridão constitucional opera-se por um declínio gradual desses valores, até mesmo mediante a destruição de normas e instituições que fornecem uma plataforma política para a busca do bem comum por pessoas que discordam entre si. Quando eleições são colocadas em descrédito para atingir fins eminentemente estratégicos de determinadas correntes políticas, por exemplo, pode-se colocar em risco o sistema como um todo apenas para o atendimento de objetivos mais imediatos.

O autor confere um lugar privilegiado ao papel da confiança na explicação dos ciclos de degradação constitucional. Tanto em um nível interpessoal como na relação entre o público e as instituições, ou entre as autoridades de diferentes partidos políticos, a desconfiança pode operar na formação de um ciclo vicioso em que atores do sistema manejam mecanismos para fragilizar as estruturas institucionais em seu favor, buscando perpetuar condições de poder político. Aqui, o autor dialoga com a já conhecida noção de jogo duro constitucional, ou constitutional hardball, do constitucionalista Mark Tushnet (2004). Se a crise, para Balkin, é compreendida como ruptura quase absoluta da Constituição como reguladora da política, a podridão é um processo gradual de erosão das 
instituições democráticas que pode corroer lentamente as estruturas constitucionais a partir de seu interior.

Cuida-se do ponto da obra que mais se aproxima das recorrentes perguntas sobre se e como as instituições funcionam (ou devem funcionar) em um regime constitucional democrático. O papel de uma Constituição, na lógica de ciclos de podridão e renovação, diz respeito à criação de mecanismos que preservem os valores democráticos e republicanos até que um novo ciclo se inicie, erigindo travas estruturais para o combate de ações de lideranças políticas que visem a preservar ou construir condições de poder à revelia das instituições. Além da polarização política, da desigualdade econômica e do aumento da desconfiança, outro fator causal importante para gerar podridão constitucional diz respeito a falhas em políticas públicas caracterizadas como verdadeiros desastres políticos. Os três exemplos de desastres trazidos do contexto norte-americano referem-se às catastróficas incursões do exército estadunidense nas guerras do Vietnam e do Iraque, além da malsucedida resposta governamental à crise financeira de 2008.

Mais uma vez, Balkin confere peso ao problema da desigualdade econômica. Em particular, trata da necessidade de ampliação de classes médias em contraposição aos incentivos da política econômica ao crescimento de riqueza no topo da cadeia (foco mais direcionado ao problema da distribuição de recursos do que sobre a pobreza propriamente dita). Nesse particular, sua análise de conjuntura toma posição contra o governo republicano de Donald Trump, a quem caracteriza como um demagogo que opera para a fragilização crescente das estruturas constitucionais, acelerando esse processo de degradação.

Em síntese, o tempo constitucional é concebido a partir da interação entre esses três ciclos históricos diferentes: (i) o ciclo de ascensão e queda dos regimes políticos; (ii) o ciclo de polarização e despolarização; e (iii) o ciclo de podridão e renovação constitucional. Seria justamente a situação atual de transição concomitante dos três ciclos que explicaria o estado de coisas da democracia constitucional estadunidense. Um alinhamento quase acidental que teria redundado em "tempos sombrios”. Se o diagnóstico não poderia ser mais negativo, seu exercício preditivo sobre o futuro apresenta praticamente uma profissão de fé no início premente de ciclos mais virtuosos. Ao final da primeira seção do livro, o autor chega a prometer que "esse eclipse é puramente temporário" (BALKIN, 2020, p. 65). 


\section{O tempo judicial e o controle de constitucionalidade}

A segunda parte do livro propõe-se a pensar o papel do controle de constitucionalidade e do Judiciário no âmbito dos três ciclos do tempo constitucional. De um lado, questiona-se qual é o efeito dos movimentos de cada ciclo histórico sobre tribunais e, de outro, qual seria o papel do controle de constitucionalidade na contenção ou no reforço das tendências cíclicas. Aqui, Balkin realiza, de forma ainda mais clara, seu papel de teórico constitucional, conectando trabalhos anteriores e a literatura sobre controle de constitucionalidade com seu pensamento sobre ciclos. Como o aparente determinismo histórico abre espaço para juízes? Qual é o papel de tribunais e do direito nesse processo aparentemente irresistível e pouco aberto à ação humana? As respostas apresentadas são sofisticadas e dialogam criticamente com refratários e entusiastas de um protagonismo político do Judiciário.

De início, essa interação de juízes com/na política é estabelecida a partir de três premissas: (i) a ideia de tempo judicial; (ii) a constatação de suportes políticos ao controle de constitucionalidade; e (iii) a relação do controle de constitucionalidade com o sistema partidário. Ao estabelecer um diálogo direto com a ciência política, o autor rompe com uma matriz idealista que marca o pensamento jurídico sobre o papel de juízes constitucionais e apresenta uma concepção do controle de constitucionalidade que se sujeita não apenas aos limites textuais do conteúdo da Constituição, mas também aos limites da realidade política.

Esse traço da obra evidencia-se logo na ideia de tempo judicial. Parte-se da literatura da ciência política, especialmente a partir de Dahl (1957), que considera a influência de coalizões governantes sobre a Suprema Corte a partir do mecanismo institucional estabelecido para nomeação dos juízes constitucionais. Balkin entende que o partido dominante influencia não apenas a composição, mas também a direção da Suprema Corte (Balkin, 2020, p. 71). O que diferencia o tempo judicial do tempo político não é uma distinção funcional entre o jurídico e o político, mas antes a diferença temporal gerada pelas engrenagens institucionais. A ideia de tempo judicial refere-se justamente ao fato de que justices da Suprema Corte têm mandato vitalício e, em função da transitoriedade de coalizões governantes no âmbito político, não há harmonia automática entre o tribunal e o partido dominante. Como exemplo dessa diferença, Balkin lembra de episódios de conflito entre a Suprema Corte dos EUA, composta por uma maioria de indicados republicanos, e os planos econômicos no New Deal do democrata 
Franklin Roosevelt, até a distensão ocasionada por novas indicações judiciais a partir de 1937.

Mas, se insatisfações políticas são geradas por conta dessa desarmonia temporal, o que confere sustentação ao controle de constitucionalidade? Tribunais não se mantêm apenas pela força da lei; são capazes de exercer seu papel institucional porque contam com suportes políticos, apesar dos descompassos ocasionais. Ou seja, as razões que subjazem a esse apoio dizem respeito a cálculos operados por políticos que percebem que o controle de constitucionalidade pode gerar benefícios; constituem motivações políticas essencialmente autointeressadas, que não correspondem a considerações normativas acerca do desenho institucional ideal, ou mesmo a uma visão localizada apenas em um lado do espectro ideológico, seja à direita ou à esquerda.

O livro elenca um inventário sistematizado dessas motivações de políticos (BALKIN, 2020, p. 75-76). Apesar de o autor não apresentar evidências para amparar suas considerações, podemos conectá-las com uma série de casos próximos à nossa realidade, bem como a estudos empíricos produzidos pela literatura estrangeira e nacional:

- Em um sistema federal com separação de poderes, como o brasileiro, tribunais poderiam servir a interesses políticos por agir para resolver conflitos horizontais (entre Poderes) e verticais (entre unidades da Federação). Em particular, políticos nacionais podem se valer de instrumentos de revisão judicial para impor sua visão sobre leis locais (WHITTINGTON, 2006);

- O exercício do controle de constitucionalidade poderia servir para estabelecer as regras básicas para regular a disputa política. Além disso, os tribunais poderiam decidir temas que dividem a arena política, desincumbindo políticos da responsabilidade por decisões que poderiam fragmentar seus partidos;

- Alguns políticos podem se valer de decisões judiciais para legitimar suas ações, qualificando-as como aderentes à lei e à Constituição, enquanto outros podem buscar os tribunais para contestar decisões políticas de seus oponentes. Ou seja, políticos encontram na arena judicial um espaço para buscar vitórias políticas ${ }^{3}$. 
Reconhecendo essa realidade política, amplamente documentada pela área de estudos judiciais, Balkin avança para uma teorização central em sua tese mais ampla. Segundo o autor, é marcante a diferença entre as razões de suportes políticos ao controle de constitucionalidade e as razões que tornam esse instrumento desejável do ponto de vista normativo. Nesse contexto, aponta que uma ampliação desse descompasso motivacional na prática constitucional pode fazer com que tribunais sejam guiados primordialmente para servir a interesses políticos, o que seria especialmente problemático em cenários de alta polarização e de degradação constitucional.

Finalmente, sobre a relação de tribunais com o sistema partidário, a obra apresenta a ideia de entrincheiramento partidário. Balkin refere-se à tentativa de partidos políticos adicionarem aliados ideológicos em cortes federais a partir do processo de nomeações judiciais como um importante catalizador da mudança constitucional. Em função do descompasso entre tempo politico e tempo judicial, governantes valem-se da prerrogativa de escolha de juízes com mandato vitalício para entrincheirar no Judiciário suas visões ideológicas e, assim, promover mudanças no direito constitucional para além de seus próprios mandatos. Essa "tradução" da "política constitucional em direito constitucional" (BALKIN, 2020, p. 80) não é percebida apenas como uma troca de peças em um tabuleiro, por meio da qual se desloca a posição do "juiz mediano”, mas como verdadeiro método de transformação do ambiente jurídico mais amplo a partir de mudanças incrementais na doutrina.

$\mathrm{O}$ autor reconhece os limites do mecanismo de indicação como forma de controle político do Judiciário, chamando esse instrumento de "ferramenta imperfeita”. Em primeiro lugar, porque o Executivo não tem um poder de livre escolha, e o Senado dispõe de mecanismos de moderação ${ }^{4}$. Adicionalmente, o próprio presidente poderá tomar em conta outros aspectos para sua escolha, que não se relacionam com posições ideológicas, como a necessidade de agradar setores de seu eleitorado a partir de indicações que favoreçam determinados estratos demográficos ou regionais. Mesmo assim, retomando trabalho anterior (BALKIN; LEVINSON, 2001), conclui que a história constitucional estadunidense conta com episódios que atestam a conexão direta entre o processo de entrincheiramento partidário do Judiciário e subsequentes mudanças constitucionais.

${ }^{4}$ Esse papel senatorial de moderação da escolha presidencial também é explorado pela literatura no caso brasileiro (LLANOS, LEMOS, 2013). 
Logo no capítulo seguinte, Balkin explora outras condições do ciclo de ascensão e queda de regimes político que afetam o controle de constitucionalidade. Mais uma vez, o processo de indicação de juízes constitucionais é destacado como principal variável explicativa da agenda da Suprema Corte. Avança, assim, a tese de que partidos políticos se utilizam da revisão judicial para realizar seus interesses.

Aqui, o autor desenvolve mais um padrão cíclico recorrente do ponto de vista histórico e que repercute em um deslocamento das atitudes de políticos e eleitores em face do exercício do controle de constitucionalidade por tribunais. Como a queda de regimes políticos não se confunde com o tempo de mandatos de juízes constitucionais, novas coalizões governantes podem lidar com um Judiciário hostil quando ascendem ao poder; por isso, tornam-se - ao menos momentaneamente - críticos do "ativismo judicial" e defensores da deferência, formando opinião convergente em seu eleitorado. Ao longo do tempo, a partir de renovações da composição de tribunais, a coalizão dominante assume uma atitude mais amigável em relação ao Judiciário, de modo que o papel crítico é transferido para a oposição. Mais uma vez, cuida-se de fenômeno gradual, que confere espaço apenas para mudanças incrementais, porém que tem como resultado líquido, ao longo do tempo, progressiva expansão do poder judicial.

Essa visão cíclica da evolução do controle de constitucionalidade e das atitudes de políticos em face de tribunais, ancorada na visão de que o próprio Judiciário é permeável às posições ideológicas de políticos (fundamentalmente por uma aderência de juízes a visões e valores daqueles que os indicam), não pode ser confundida com a visão corrente no debate público que postula uma aderência quase automática de juízes constitucionais aos interesses dos presidentes responsáveis por sua nomeação. Mais ainda, no contexto multipartidário brasileiro, em que há uma demarcação ideológica bem menos clara do que nos EUA, essa resposta torna-se menos atraente. Enquanto o caso Bush v. Gore ainda é difícil de ser superado pela teoria jurídica norte-americana, por aqui há inúmeros casos recentes em que ministros decidiram contrariamente aos interesses de partidos responsáveis por sua indicação. Se, em tese, ministros têm algum incentivo para alinhamento a interesses partidários, esses parecem ser contrabalanceados na realidade institucional por vários outros aspectos que favorecem maior autonomia judicial.

Mais interessante é o papel que Balkin confere aos ciclos do controle de constitucionalidade sobre visões da teoria constitucional acerca do papel 
jurisdicional. Trabalhando a partir da análise das duas escolas mais influentes no contexto norte-americano - originalismo e constitucionalismo vivo -, o autor demonstra como o pensamento constitucional mais crítico aos excessos de poder judicial não corresponde a uma perspectiva teórica mais profunda, mas antes à posição ocasional de tribunais no espectro político-ideológico. Ou seja, teorias mais vinculadas a valores conservadores (originalismo) criticam o "ativismo judicial" de decisões mais progressistas (e.g. caso Roe v. Wade), enquanto teorias mais progressivas (constitucionalismo vivo) são mais refratárias a tribunais que bloqueiam políticas consistentes com suas convicções (e.g. era Lochner).

Cuida-se, por conseguinte, de um ciclo de pensamento constitucional que também se relaciona com os ciclos do tempo constitucional, mas que se desenvolve em momentos distintos. A formação de teóricos a partir de um determinado contexto molda doutrinas que exercem influência acadêmica por toda uma geração. Por exemplo, originalistas que formulam suas teorias em um momento de ascensão de regimes liberais tendem a desenvolver doutrinas mais céticas em relação ao papel judicial, e essas ideias constitucionais sobrevivem àquela ocasião específica, produzindo efeitos ideacionais que superam a queda daquele regime político. O ciclo da teoria constitucional caminha a reboque de mudanças no campo político-institucional. Ao contrário de explicações ideacionais, que tentam demonstrar como ideias influenciam a construção institucional, Balkin apresenta um raciocínio causal inverso; é o ciclo dos regimes políticos que dá o tom de teorias e de suas visões sobre o controle de constitucionalidade.

O estágio do ciclo de polarização também tem reflexos sensíveis sobre o exercício do controle de constitucionalidade. Em um ambiente político despolarizado, partidos costumam reconhecer, de forma mais consensual, o papel judicial no estabelecimento das regras básicas do jogo político. Ocorre que, à medida que a polarização alcança níveis extremados, elites governantes deixam de compartilhar um conteúdo básico de suposições comuns. Ou seja, mesmo essa regulação mais básica do processo político assume contornos mais polêmicos e potencialmente partidarizados. Isso molda não apenas as opiniões das elites, mas também alcança os próprios bancos judiciais ao longo do tempo. A cisão de consensos das elites ocasionada pela polarização extremada impacta não apenas as atitudes de políticos em face de tribunais, mas também o próprio pensamento jurídico de juízes.

Nesse sentido, a polarização elidiria a distinção proposta por Balkin entre high politics, que diz respeito aos valores e princípios constitucionais mais 
básicos, e low politics, que corresponde às disputas partidárias mais triviais. Também se torna mais difícil perceber ou antecipar o sentido da história, mas os caminhos propostos tanto por políticos como por juízes são opostos. Assim, a polarização faz com que o propósito de avançar interesses ideológicos pela via judicial se sobreponha à concepção do Judiciário como garante constitucional do jogo político.

Além disso, visto que a polarização tem um efeito paralisador sobre o processo político, há uma tendência de se demandar, de forma mais contundente, a intervenção judicial em políticas públicas. Por isso, Balkin percebe que o papel de tribunais que exercem o controle de constitucionalidade transita da imagem de árbitros do jogo político para o exercício de uma vanguarda política. A ideia de vanguarda, concebida como "uma força que está à frente", aplica-se não porque tribunais "podem fazer tudo isso", mas antes porque são incumbidos de continuar o trabalho que políticos não conseguem fazer (BALKIN, 2020, p. 128).

Com efeito, a vanguarda política de Balkin é bastante semelhante, mas caminha no sentido oposto da vanguarda iluminista de Luís Roberto Barroso ${ }^{5}$. Para o juiz constitucional brasileiro, a vanguarda também significa que a corte é “[... encarregada de empurrar a história quando ela emperra [...]” (BARROSO, 2015, p. 42), mas esse papel é arriscado e deve ser exercido com parcimônia. No entanto, a vanguarda iluminista caminha para verdadeiros "avanços sociais", de modo que esse exercício seria imprescindível para o progresso da sociedade (Barroso, 2015, p. 43). Na visão do norte-americano, contudo, depositar os anseios de transformação social a essa vanguarda togada não é apenas arriscado, mas constitui verdadeira disfunção da democracia constitucional. A impressão de que juízes estariam à frente de seu tempo não passaria de ilusão gerada pelo fato de que "[...] eles têm condições de agir quando políticos não têm [...]" e, por isso, acabam por promover "[...] ativamente os valores de um partido altamente polarizado [...]" (BALKIN, 2020, p. 129). Isso tornaria o Judiciário um objeto ainda mais candente de disputa política e ampliaria a desconfiança sobre a Suprema Corte, concorrendo para o processo mais amplo de degradação constitucional (BALKIN, 2020, p. 134).

Em face dessas considerações, Balkin não reserva papel proeminente ao direito e às instituições judiciais na contraposição a movimentos negativos dos

Para uma reflexão crítica sobre a visão de Barroso, ver Miguel e Bogéa (2020). 
ciclos do tempo constitucional. Tribunais não têm capacidade para atuar em sentido contrário a movimentos cíclicos de podridão constitucional, de polarização e de declínio de um regime político. Logo, não são parte da solução e, muitas vezes, podem contribuir com os problemas. Corre-se o risco de uma quebra das fronteiras entre princípios constitucionais e interesses partidários, fazendo com que a disputa por influência em tribunais assuma primazia na política eleitoral, até mesmo por mecanismos mais próximos do mencionado jogo duro constitucional. Com isso, em vez de funcionar como contrapeso ao entrincheiramento político, tribunais podem exacerbá-lo, de modo que a vanguarda política não se confunde com uma vanguarda de proteção da democracia e de renovação constitucional (BALKIN, 2020, p. 143-144).

O controle de constitucionalidade não deixa de ser percebido pelo autor como uma engrenagem relevante no funcionamento da democracia constitucional. Todavia, cuida-se de ferramenta que gera melhores resultados quando o sistema como um todo é funcional, não sendo apropriado percebê-la como uma trincheira de combate a movimentos cíclicos do tempo constitucional. Como conclui, “[...] em uma época de avançada podridão constitucional, podemos não ser capazes de depender do judiciário quando mais precisamos dele" (BALKIN, 2020, p. 147).

\section{Conclusão}

Em The Cycles of Constitutional Time, Jack Balkin dá mostras de seu pensamento constitucional sofisticado, conectando-o com um domínio invejável dos debates de fronteira sobre o Judiciário na ciência política. Em prosa fácil, propõe instrumental teórico inovador para a análise da conjuntura política estadunidense, descendo ao que compreende como as raízes do conturbado momento atual. A ideia de concomitância de transições em três ciclos históricos do tempo constitucional promete exercer influência sobre o debate público e acadêmico nos EUA, mas também oferece ferramentas para pensarmos outras realidades.

Como diagnóstico, o livro apresenta ao leitor um excelente panorama factual do funcionamento dos poderes na democracia constitucional estadunidense. Esse mérito se amplifica na medida em que apresenta de forma transparente seu posicionamento no espectro ideológico. De toda maneira, cumpre observar que a obra abre flancos para críticas. Em primeiro lugar, a concepção da história a partir de ciclos está muito longe de assumir um lugar dominante na academia, 
de modo que a interpretação pode ser alvo de perspectivas alternativas que são igualmente compatíveis com o atual estado de coisas e menos deterministas. Mesmo a partir de um olhar interno ao argumento, também pode-se apontar a ausência de pontes claras entre os três ciclos do tempo constitucional, sendo pouco crível que eles realmente caminhem de forma absolutamente independente.

Como exercício preditivo, o livro apresenta a esperança em um futuro melhor, mas não a deposita sobre o Judiciário, que funcionaria como um "indicador atrasado da política” (BALKIN, 2020, p. 10). Esse otimismo é refém da percepção cíclica da história, pois é devedor de uma expectativa de que vivemos um momento de eclipse temporal e de que a renovação constitucional e a despolarização fazem parte de nosso destino histórico. Há pouco espaço para a ação humana, em uma perspectiva estruturalista que contrasta com a crítica inicial do autor ao determinismo histórico. Adicionalmente, não são apresentadas evidências empíricas suficientes para sustentar posições como, por exemplo, a ideia de que o pico do ciclo de polarização foi alcançado.

Nada obstante, é de se reconhecer que a visão de que "[...] nós não devemos tratar cortes como salvadores nesse período difícil” (BALKIN, 2020, p. 11) não apenas é consistente com o relato descritivo da história constitucional, mas também oferece o ponto de partida do trecho mais fértil do livro sobre o funcionamento das instituições democráticas. Balkin formula um inventivo receituário de reformas institucionais para a Suprema Corte dos EUA que é consistente com essa visão. Não se avança sobre a recorrente ideia de empacotamento daquele tribunal a partir do aumento do número de juízes constitucionais, mas são defendidas quatro propostas concretas:

1. A instituição de indicações mais regulares e previsíveis de justices da Suprema Corte, com uma distribuição equitativa do número de nomeações ao longo de diferentes mandatos presidenciais. Isso se daria a partir da nomeação de uma nova juíza a cada dois anos;

2. A criação de limites práticos aos mandatos de justices, operados a partir de ferramentas de controle do quórum de julgamento pelo Congresso, com o propósito de regularizar e tornar mais previsível o processo de entrincheiramento partidário, reduzindo os incentivos para jogo duro constitucional;

3. A redução dos poderes da Suprema Corte na definição de sua própria pauta (poder de agenda), aumentando o número de casos para sua apreciação; 
4. A implementação de reformas legislativas com cláusulas do tipo sunrise, que passam a ter efeitos apenas em uma data futura predeterminada, de modo a despolarizar o ambiente político e restaurar a confiança no Judiciário.

Por mais que se trate de propostas interessantes (e polêmicas), são próprias ao contexto estadunidense e ao desenho daquele tribunal. É de se notar, no entanto, como o autor atribui ao aumento do número de casos a redução do controle da Corte sobre sua agenda, servindo de ferramenta de despolarização, pois reduziria a "temperatura política" dos julgamentos. No caso do STF, por exemplo, essa temática também vem sendo endereçada pela literatura, destacando-se a existência de mecanismos que permitem o controle da agenda, mesmo diante da demasiada quantidade de processos que chegam ao Supremo (ARGUELHES; HARTMANN, 2017).

Cumpre indagar o que obra pode dizer sobre o momento constitucional brasileiro e, de forma mais geral, como as ferramentas teóricas de Balkin podem ser aplicadas em estudos constitucionais comparados. O próprio autor reconhece que "[...] instituições diferentes com histórias diferentes tendem a absorver choques e influências de forma diferente" (BALKIN, 2020, p. 10). Em todo caso, cuida-se de trabalho que merece ser conhecido e que tem o potencial de influenciar a produção de uma teoria constitucional brasileira mais informada pela realidade institucional e pela literatura da ciência política. Vale resgatar, ainda, uma conclusão central que pode servir para reflexões sobre as expectativas sociais a serem depositadas no STF: "Nós não devemos esperar que os tribunais nos salvem da degradação constitucional. Só a mobilização democrática pode fazer isso" (BALKIN, 2020, p. 150). 


\section{Referências}

ARGUELHES, Diego Werneck; HARTMANN, Ivar A. Timing control without docket control: how individual justices shape the Brazilian Supreme Court's agenda. Journal of Law and Courts, v. 5, n. 1, pp. 105-140, 2017.

BALKIN, Jack. The cycles of constitutional time. New York: Oxford University Press, 2020.

BALKIN, Jack; LEVINSON, Sanford. Understanding the constitutional revolution. Virginia Law Review, v. 87, n. 6, p. 1045-1109, 2001.

BARROSO, Luís Roberto. A razão sem voto: o Supremo Tribunal Federal e o governo da maioria. Revista Brasileira de Políticas Públicas, Brasília, v. 5, Número Especial, p. 23-50, 2015. Disponível em: https://www. publicacoesacademicas.uniceub.br/RBPP/article/viewFile/3180/pdf. Acesso em: 10 jun. 2021.

BOGÉA, Daniel. Partidos políticos e STF: decifrando a simbiose institucional. Curitiba: Appris, 2021.

DA ROS, Luciano. Tribunais como árbitros ou como instrumentos de oposição: uma tipologia a partir dos estudos recentes sobre judicialização da política com a aplicação ao caso brasileiro contemporâneo. Direito, Estado e Sociedade, n. 31, p. 86-105, 2007. Disponível em: https://direitoestadosociedade.jur.puc-rio. br/media/Ros_n31.pdf. Acesso em: 10 jun. 2021.

DAHL, Robert. Decision-making in a democracy: the Supreme Court as a national policy-maker. Journal of Public Law, v. 6, n. 2, p. 279-295, 1957.

GINSBURG, Tom; HUQ, Aziz Z. How to save a constitutional democracy. Chicago: University of Chicago Press, 2018.

LEVITSKY, Steven; ZIBLATT, Daniel. How democracies die. New York: Broadway Books, 2018.

LLANOS, Mariana; LEMOS, Leany Barreiro. Presidential preferences?: the Supreme Federal Tribunal nominations in democratic Brazil. Latin American Politics and Society, v. 55, n. 2, p. 77-105, 2013. 
MIGUEL, Luis Felipe; BOGÉA, Daniel. O juiz constitucional me representa?: o Supremo Tribunal Federal e a representação argumentativa. Revista Brasileira de Ciências Sociais, v. 35, n. 104, p. 1-21, 2020. Disponível em: https://www. scielo.br/j/rbcsoc/a/XVsvWQHJXRSQpVDQfTH8nXc/?lang=pt. Acesso em: 10 jun. 2021.

PRZEWORSKI, Adam. Crises of democracy. New York: Cambridge University Press, 2019.

SUNSTEIN, Cass (ed.). Can it happen here?: authoritarianism in America. New York: Dey Street Books, 2018.

TAYLOR, Matthew. El Partido de los Trabajadores y el uso político del poder judicial. América Latina Hoy, n. 37, p. 121-142, 2004. Disponível em: https:// revistas.usal.es/index.php/1130-2887/article/view/7563/7572. Acesso em: 10 jun. 2021

TAYLOR, Matthew; DA ROS, Luciano. Os partidos dentro e fora do poder: a judicialização como resultado contingente da estratégia política. Dados - Revista de Ciências Sociais, v. 51, n. 4, p. 825-864, 2008. Disponível em: https://www. scielo.br/j/dados/a/ybwH5kBrjcBWKX8mVqgzR4r/?lang=pt\&format=pdf. Acesso em: 10 jun. 2021.

TUSHNET, Mark. Constitutional hardball. Marshall Law Review, v. 37, 2004. Disponível em: https://scholarship.law.georgetown.edu/cgi/viewcontent. cgi article $=1557 \&$ context=facpub. Acesso em: 10 jun. 2021.

WHITTINGTON, Keith. Preserving the dignity and influence of the court: political supports for judicial review in the United States. In: SHAPIRO, Ian; SKOWRONEK, Stephen; GALVIN, Daniel (ed.) Rethinking political institutions: the art of the state. New York: NYU Press, 2006. 